\title{
Reports
}

\section{Opioid crisis: a public health concern in Colorado, United States}

\author{
Adeyemi A. Adeosun ${ }^{1}$ \\ ${ }^{1}$ Health Initiative Department, National Jewish Health, Denver, Colorado, USA \\ Keywords: global health \\ https://doi.org/10.29392/joghr.3.e2019056
}

\section{Journal of Global Health Reports}

Vol. 3, 2019

\begin{abstract}
Opioids have become one of the leading substances abused across many cities in the United States (US), with opioid use disorder already a public health concern. Most of the opioid-related deaths are due to prescription medication. In 2017, opioid overdose was responsible for 560 deaths in Colorado, representing 5.8 deaths per 100,000 residents. Women and children are increasingly affected, implying a need for concerted efforts to address it. Despite an alarming rate of opioid crisis among pregnant women, direct health consequences, especially Neonatal Abstinence Syndrome (NAS), are not clearly covered by health insurance schemes in Colorado, which significantly affects care and overall public health response. In this paper, the impact of opioids on maternal and child health in Colorado is examined, with recommendations towards improving overall management response.
\end{abstract}

Opioids belong to a class of drugs used to reduce pain. This includes heroin, synthetic opioids such as fentanyl, and prescription pain relievers like oxycodone, hydrocodone, codeine, and morphine. ${ }^{1}$ They generally act on opioid receptors to produce morphine-like effects. Opioids have become one of the leading substances abused across many cities in the United States (US), with opioid use disorder already a public health concern. ${ }^{2}$ Opioid abuse negatively impacts individuals, families, and communities. In 2018, two million Americans were estimated to suffer from addiction to opioids amidst reports that USA is the largest per capita consumer of pain pills globally. ${ }^{3}$

From 2013 to 2017, synthetic opioids contributed to a rise in drug overdose death rates in the US, with over 1600 prescription opioid-related deaths recorded across several states. ${ }^{4}$ Between 2016 and 2017, synthetic opioid-involved overdose death rates increased by $45.2 \%$. In 2017, opioid overdose was responsible for 560 deaths in Colorado; this translates to 5.8 deaths per 100,000 residents. ${ }^{5}$ Over the same period, Heroin overdose-related deaths in Colorado increased by $77 \%$, which translates to 3.2 deaths per 100,000 residents. ${ }^{4,5}$ National overdose deaths involving any opioid rose from 8048 in 1999 to 47,600 in 2017. ${ }^{1}$

Most of the opioid-related deaths are due to prescription medication. In 2018, President Donald Trump declared war against opioid prescription with over 4.6 billion United States dollars allocated to fight opioid crisis at the national and state levels. ${ }^{6}$ Although reports show that opioids abuse has contributed to increased morbidity and mortality across different age groups in the US, women and children are increasingly affected, implying a need for concerted efforts to address this problem. In this paper, the impact of opioids on maternal and child health in Colorado is briefly examined with recommendations towards improving overall management response.

\section{OPIOIDS USE AMONG PREGNANT WOMEN}

Women experience several hormonal and physiological changes in pregnancy, often associated with psychological, social and emotional changes which can trigger the use of psychotropic medication as a form of coping. In the period 2008-2012, opioid prescription was both high among Medicaid-enrolled women (39\%) and privately insured women (28\%), with most frequently prescribed opioids being hydrocodone, codeine, and oxycodone. In 2017, 22\% $(n=1,299,541)$ of all prescription medication was dispensed to women of reproductive age (15-44 years) in Colorado. ${ }^{7}$

Although substance use rates are generally higher among men compared to women, women are more likely to use prescription opioids and suffer from their effects, including relapse and cravings. ${ }^{7}$ Women have been found to be at greater opioid use across all age groups as they tend to report their pain experience more frequently, have higher rates of pain-related diagnoses, and demonstrate variable responses to pain and analgesia. For example, women enrolled in Medicaid Managed Care Organization (MMCO) filled more opioid prescription than men in Colorado, US (63\% vs $37 \%){ }^{8}$

There are four main groups of pregnant women that use opioids. These include: (i) those taking medication for pain (monitored by a physician and are not addicted); (ii) those on medication-assisted treatment (MAT) who are recovering from a substance use disorder (also managed by a physician); (iii) those misusing opioid pain medications with or without prescription (addicted); and (iv) those using illicit opioids (e.g., heroine) and who are addicted. ${ }^{1,2}$ 


\section{OPIOIDS EXPOSURE AND CHILDREN'S DEVELOPMENTAL MILESTONES}

Although opioid exposure in utero is associated with perinatal morbidity and mortality, long-term neurodevelopmental outcome in children is a major concern. Increase in the use of opioids among pregnant women may be associated with health consequences, particularly in the early developmental stages of children. For example, prevalence of Neonatal Abstinence Syndrome (NAS) increased by over $80 \%$ between 2010 and 2015 in Colorado, a period relatively covered in the 2013-2017 opioid use surge in the US. ${ }^{4}$

NAS is a term for a group of problems a newborn experiences when withdrawing from exposure to narcotics in utero. ${ }^{9}$ Chronic use of an opioid during pregnancy has been associated with NAS. Among 201,275 pregnant women with public insurance who were exposed to opioids around the time of delivery, prescriptions for other psychotropic medication in particular antidepressants, atypical antipsychotics, benzodiazepines, gabapentin, and non-benzodiazepine hypnotics with opioid, were filed at about the same time. ${ }^{10}$ Studies showed that some children tend to experience cognitive, behavioral, developmental and educational challenges following recovery from NAS, which is particularly important in the long-term management of such children. ${ }^{11}$ Post NAS children are more likely to experience poor performance in school, low self-esteem, emotional and behavioral problems. Besides, a higher risk of physical, verbal and sexual abuse, along with anxiety and depression have also been reported. Another important concern is the concurrent use of opioids with other stimulants reported in some US settings, which further increase the risk and severity of neonatal abstinence syndrome. For example, the absolute risk for neonatal drug withdrawal symptoms ranged from $1.0 \%$ in infants exposed in utero to prescription opioids alone to $11.4 \%$ for those exposed to opioids co-prescribed with gabapentin. It has been observed that women addicted to prescription medications may resort to recreational drugs if denied a new prescription, thus making the overall severity of health consequences like NAS worse. Besides, women using recreational drugs are at higher risk of HIV and hepatitis propagated by sharing of needles and high-risk sexual behavior.

Foster and adoptive children exposed to opioid and polysubstance abuse in utero do not cognitively catch up over time. Exposed children also lag behind the non-exposed children all through infancy and into school age even when placed in a low-risk stable family. ${ }^{12}$ The social impact has also been widely reported, with opioid crisis now forcing grandparents to raise their grandchildren while their own children are battling addiction to opioids. ${ }^{13}$

The economic impact has been relatively high, with $84.3 \%$ of persons suffering from drug dependence or abuse who remain untreated in Colorado. In 2012, Medicaid paid over $81 \%$ of the $\$ 1.5$ billion United States dollars billed for hospitals for treating babies suffering from opioid withdrawal alone.

\section{RESPONDING TO OPIOID CRISIS IN COLORADO}

Despite an alarming rate of opioid crisis among pregnant women and increase in NAS in the last decades, NAS and post-NAS treatment are not included in insurance coverage in Colorado, which significantly affects care and overall public health response. First, a multidisciplinary approach is recommended to achieve meaningful impacts. Researchers, physicians, pharmacists, social workers, spiritual counselor, nurses, psychologist, lawmakers, physiotherapy, speech-language pathologist, among many others, all have important roles to play in ensuring an effective response. A framework on how best to develop an effective intervention that spreads across all and accepted by the government and insurance coverage can be the subject of further studies. Meanwhile, in Colorado, more needs to be put in place to monitor the prescription of opioids, especially during pregnancy. Testing for opioids early in pregnancy may need to be considered, with the health providers using various resources to support mother both physically and mentally when relevant. Screening during third trimester is also recommended for every pregnant woman at risk, with appropriate treatment and psychosocial support made available to mothers and childen after birth. A child diagnosed with NAS needs to be closely monitored at a neonatal intensive care unit. It is recommended that such child be followed-up during childhood for any medical or developmental issues. The mother also needs to be followed up at an addiction clinic. Also, more addiction counselors need to be employed to each school to support teachers during school hours and educate the children about drug addiction, while at the same time not denying the child the social interaction with his/her peers. Attention should be given to behavioral, language, gross motor, social and neurodevelopmental milestones. As noted, it is important that health consequences from opioid abuse like NAS (and post-NAS treatment) be considered in Medicaid coverage. While all stakeholders need to consider how best this can work, continued awareness, advocacy, and relevant studies may likely make some impact, especially in Colorado.

\section{ACKNOWLEDGEMENTS}

The authors would like to thank Dina Johnson and Renee Charlifue-Smith for the support in the writing of the manuscript.

\section{FUNDING}

None.

\section{COMPETING INTERESTS}

The author completed the Unified Competing Interest form at http://www.icmje.org/coi disclosure.pdf (available upon request from the author), and declare no conflicts of interest. 


\section{CORRESPONDENCE TO:}

Dr Adeyemi Abraham AdeosunHealth Initiative DepartmentNational Jewish HealthDenver, ColoradoUSAadexson217@yahoo.com 


\section{REFERENCES}

1. National Institute on Drug Abuse. Drugs of abuse: Opiods. Published 2018. Accessed June 1, 2019. http s://www.drugabuse.gov/drugs-abuse/opioids

2. Colorado Department of Human Services. Opioid Crisis in Colorado: The Office of Behavioral Health's Role, Research and Resources. Published online 2019. Accessed June 15, 2019. https://www.colorado.gov/pa cific/cdhs/opioid-crisis-colorado-office-behavioral-he alths-role-research-and-resources

3. Kopf D. The surprising geography of opioid use around the world. Published 2018. Accessed June 6, 2019. https://qz.com/1198965/the-surprising-geograp hy-of-opioid-use-around-the-world/

4. Scholl L, Seth P, Kariisa M, Wilson N, Baldwin G. Drug and opioid-involved overdose deaths-United States, 2013-2017. MMWR Morb Mortal Wkly Rep. 2018;67(5152):1419. doi:10.15585/mmwr.mm675152e 1

5. Metz TD, Rovner P, Hoffman MC, Allshouse AA, Beckwith KM, Binswanger IA. Maternal Deaths From Suicide and Overdose in Colorado, 2004-2012. Obstet Gynecol. 2016;128(6):1233-1240. doi:10.1097/aog.000 0000000001695

6. Mulvihill G. Federal budget deal includes $\$ 4.6$ billion to combat opioid epidemic. The Washington Post. 2018.

7. Serdarevic M, Striley CW, Cottler LB. Sex differences in prescription opioid use. Curr Opin Psychiatry. 2017;30(4):238-246. doi:10.1097/yco.0000 $\underline{000000000337}$
8. Hernandez AA, Moore JE. The US opioid epidemic: an overview of clinical and policy responses to address opioid misuse In the Mecaid program. Published 2017. Accessed June 19, 2019. https://ww w.medicaidinnovation.org/_images/content/4._Overvi ew_of_Clinical_and_Policy_Responses to Address_Opi oid_Misuse in the Medicaid_Program_pdf

9. Towers CV, Hyatt BW, Visconti KC, Chernicky L, Chattin K, Fortner KB. Neonatal Head Circumference in Newborns With Neonatal Abstinence Syndrome. Pediatrics. 2019;143:e20180541. doi:10.1542/peds.201 $\underline{8-0541}$

10. Huybrechts KF, Bateman BT, Desai RJ, et al. Risk of neonatal drug withdrawal after intrauterine coexposure to opioids and psychotropic medications: cohort study. BMJ. 2017;358:j3326. doi:10.1136/bmj.j $\underline{3326}$

11. Proctor-Williams K. The Opioid Crisis on Our Caseloads: Babies born addicted to opioids can show immediate neurological and feeding problems. Studies also point to longer-term effects. ASHA Lead. 2018;23(11):42-49. doi:10.1044/leader.ftr1.2311201 $\underline{8.42}$

12. Nygaard E, Moe V, Slinning K, Walhovd KB. Longitudinal cognitive development of children born to mothers with opioid and polysubstance use. Pediatr Res. 2015;78(3):330-335. doi:10.1038/pr.2015.95

13. Bauman V. How the opioid crisis is forcing more grandparents to care for their grandchildren as their own kids battle addiction in states blighted by overprescription of the drugs - and the problem is worst in the South. Daily Mail UK. 2019. 